\title{
J. Wouters, P. De Man, R. Hansen (eds.), Commercial Uses of Space and Space Tourism - Legal and Policy Aspects, Elgar 2017, 303 pages.
}

Commercial use of Outer Space is a topic that undoubtedly induces interest and tensions. For some, Outer Space should be primarily considered as a global commons or global public goods where the idea of commercial use seems significantly ancillary. ${ }^{1}$ For others, commercial use is a right and already established fact stemming from fundamental principles of international Space law, in particular, of freedom of exploration. ${ }^{2}$

The editors of the book undertook a remarkable initiative to combine legal, political and commercial aspects of the use of Space. As a result, among the authors of the individual chapters are the members of the academia, governmental experts, international organizations officials and representatives of industry. Taking into account the multi-faceted and future oriented approach of the editors, it is striking they devote in their introduction, significant consideration to the issue (as old as human Space activities) of the need of clear boundary between Air Space and Outer Space (p. XV-XVI).

Part I of the book "Legal challenges", starts with the contribution of Armel Kerrest concerning the concept of the launching state, which the author considers as a "central in modern Space law" (p. 3). In this respect, he notices, i.a. the problematic character of transfer of ownership

1 Ł. Kułaga, Space Mining Governance from the Perspective of International Consultations with regard to Marine Genetic Resources and the Multilateralism-Unilateralism DichotomyPreliminary Considerations, "Polish Review of International and European Law" 2017, vol. 6, no 2, p. 74 .

2 Art. I of the 1967 Treaty on Principles Governing the Activities of States in the Exploration and Use of Outer Space, Including the Moon and Other Celestial Bodies. 
of a satellite in orbit, which in his view, should be clarified by the international community (however, without treaty amendments). Moreover, when assessing the regime of Liability Convention he notices that the Stateto-State character of the procedure envisage by it can be a drawback. Nevertheless, in situations when obtaining compensation through domestic courts by the victim of Space objects would be impossible, he considers this interstate mechanism as a potential safety net (p. 10). Lesley Jane Smith, in her chapter related to managing liability for Commercial Space activities, underlines the difference between the regime of Outer Space and international aviation from the perspective of undertaking operations by private entities. She draws attention to the specific character of liability for the activities of Space Objects that can be unlimited in amount and in time. She then calls for the combine work of aviation and Space law experts for introducing a dedicated scheme for sub-orbital flights (p. 36). Next, the contribution of Steven Wood concentrates on the scope of international obligation of rescue assistance under the Outer Space Treaty and the Return and Rescue Agreement. By referring to different methods of interpretation, as contained in the Vienna Convention on the Law of the Treaties, he concludes that both of abovementioned treaties cover "all persons on board of spacecraft located in Outer Space and in need of assistance" (p. 62). Thus, these obligations also apply to private commercial passengers. Ward Munters in the chapter, "Small satellites, large constellations and Space debris: in dubio pro LEO?" addresses the issue of small satellite technology and its application in large constellations. He notices the growing interest in small satellite technology as it, by benefiting from the miniaturization of electronics, significantly reduces the costs of outer space activities. He also points out that this phenomenon is being discussed in both subcommittees (Scientific and Technical and Legal) of the United Nations Committee on the Peaceful Use of Outer Space (UN COPUOS): i.e. the International Telecommunication Union and The Inter-Agency Space Debris Coordination Committee. In these forums, some concerns are expressed with respect to the influence of the broad use of small satellites on the sustainability of Outer Space, in particular, as regards Space debris (p. 75). He warns that a collision of a mega-constellation operating in the sphere surface around the Earth "would irreversibly affect orbits at the operational altitude for several centuries or millennia" (p. 85). The concerns expressed by the author regarding the application of the rules of international law regarding transboundary activity are, additionally, interesting. Specifically, he is of the view that conclusions of the International Court of Justice from 
the Pulp Mill judgment ${ }^{3}$ in this respect have significant bearing on plans to use mega-constellations.

Part II of the book "Regulatory responses" starts with the text of Andrea J. Harrington on US State Spaceflight Liability and Immunity Acts. The author underlines the importance of the topic by stating that the appropriate liability regime can promote the growth of the Space industry, as well as ensure the protection of consumers. American Space-oriented legislation is also under scrutiny in the following chapter written by Daniel P. Murray regarding "Commercial Space operations within an existing national legal framework: some lessons learned and the challenges ahead". Jeremy Stubbs, in the following piece, concentrates on "Developing a new safety regulatory system for commercial sub-orbital space planes in the UK (...)". He advances important operational and regulatory considerations that are necessary to be taken into account when the state wants to enable the emergence of the sub-orbital domestic industry. The special character of the next chapter "Red tape in the final frontier: Bigelow Aerospace's adventures in export control" flies from the fact that it authors, Mike N. Gold and Christopher M. Hearsey, illustrate the regulatory obstacles that industry can face when developing Space capabilities. Their text is devoted particularly to the US International Traffic in Arms Regulation, that when broadly implemented, "crippled commercial space projects" (p. 162).They also provide detailed review of the evolution of US export control regime, underlying differences in the National Defense Authorization Act for Fiscal Year 2013, which enabled the creation of the model of supporting domestic industry without prejudice to national security and foreign policy objectives.

At the beginning of Part III, in the article "Space governance", Thierry Heman and Alexander Soucek propose several elements for discussion as regards "Regulatory choices for sub-orbital flights carrying humans (...)". They remind us about the beginnings of air transportation in 1920s, the characteristics, of which, are comparable to current challenges relating to sub-orbital flights. The authors are of the view that the lack of internationally accepted boundaries between Air Space and Outer Space does not influence the issue of establishing an optimal regulatory regime with regard to sub-orbital flights (p. 215). They rightfully notice that what makes it difficult to find an appropriate legal approach in this

3 Pulp Mills on the River Uruguay (Argentina v. Uruguay), ICJ Judgment of 20.04.2010, ICJ Reports 2010, p. 14. 
respect "is the heterogeneity of activities falling under the broad term Sub-orbital Flight" (p. 217). Jean-Bruno Marciacq, in the chapter on the possible role of European Aviation Safety Agency as regards Sub-orbital and Orbital flights, advances the opinion that they can be performed by aircraft, as opposed to rockets (p. 228). The author indicates that contrary to the USA, in continental Europe, all suborbital flight programmes were abandoned - which had a consequence in freezing regulatory activities at the level of the EU in this respect (p. 239). Jean-Francois Mayence provides critical remarks on the role of the UN COPUOS, which in his view is "not in phase with the development of global economic governance" and "has not shown any proactive interest in incorporating commercial actors in its work" (p. 257). He regrets that even in the Working Group on Long-Term Sustainability of Space Activities, direct participation of commercial space sector was not allowed. Simultaneously, he rightfully points out the benefits of participation of non-state actors in the regulation-making process from the point of view of the effectiveness of a regulation. Furthermore, he notices that the fault is not only on the side of UN COPUOS - as the private sector lacks the ability to use UN language for presenting its contribution. He makes an additional and important point that national law alone is currently of fundamental significance with respect to regulation of space activities, as it often goes beyond the pure implementation of the outer space treaties of the United Nations. Ending the chapter, the text of Katrin Nyman-Metcalf is devoted to the issue of self-regulation in Outer Space. The term "self-regulation" is understood by the author as "regulation by those same subjects that are the ones being regulated or at least regulation by their peers, by creating some form of a regulatory body such as an industry association or similar" (p. 268). As the definition seems to be very broad, her text constitutes a mélange of acknowledging the importance in Outer Space legislation of soft law (EU Code of Conduct, cooperation of space agencies), domestic regulation and treaties prepared under auspice of expert bodies (UNIDROIT). The author touches upon one further very interesting issue - the privatization of INMARSAT and INTELSAT (p. 276), but without discussion whether this model can be developed in future.

The book "Commercial Uses of Space and Space Tourism - Legal and Policy Aspects" is an important and significant contribution to the pertinent discussion on the mode of broadly understood Outer Space governance. One can only agree with the editors that there is a great need to adapt "ageing treaty framework to today's very different realities, spurred by these developments" (p. XVII). Thus, from the legal point of view it is to be regretted that the issue of subsequent agreements and subsequent 
practice in relation to the interpretation of Outer Space treaties was not discussed in the book.

Łukasz Kułaga*

* Ph.D., Faculty of Law and Administration, Cardinal Stefan Wyszyński University, Warsaw 